\title{
Origin and Route of Tangentially Migrating Neurons in the Developing Neocortical Intermediate Zone
}

\author{
Nobuaki Tamamaki, Kazuhiro E. Fujimori, and Rumiko Takauji \\ Department of Anatomy, Fukui Medical School, Matsuoka, Fukui 910-11, Japan
}

Neuroblasts produced in the ventricular zone of the neocortex migrate radially and form the cortical plate, settling in an insideout order. It is also well known that the tangential cell migration is not negligible in the embryonic neocortex. To have a better understanding of the tangential cell migration in the cortex, we disturbed the migration by making a cut in the neocortex, and we labeled the migrating cells with $1,1^{\prime}$-dioctodecyl-3,3,3',3'tetramethylindocarbocyanine perchlorate (Dil) in vivo and in vitro. We also determined the birth dates of the cells.

Disturbance of tangential cell migration caused an accumulation and disappearance of microtubule-associated protein 2 immunoreactive (MAP2-IR) cells on the ventral and dorsal side of the cut, respectively, which indicated that most of the MAP2-IR cells in the intermediate zone (IZ) were migrating toward the dorsal cortex. The Dil injection study in vivo con- firmed the tendency of the direction of cell migration and suggested the origin of the cells to be in the lateral ganglionic eminence (LGE). Dil injection into the LGE in vitro confirmed that the LGE cells cross the corticostriatal boundary and enter the $I Z$ of the neocortex. The migrating cells acquired multipolar shape in the $I Z$ of the dorsal cortex and seemed to reside there. A 5-bromo-deoxyuridine incorporation study revealed that the migrating MAP2-IR cells in the IZ were early-generated neurons. We concluded that the majority of tangentially migrating cells were generated in the LGE and identified as a distinct population that was assumed not to have joined the cortical plate.

Key words: Dil; intermediate zone; MAP2; lateral ganglionic eminence; neocortex; tangential cell migration
It is well known that neuroblasts produced in the ventricular zone of the neocortex migrate radially toward the neocortical surface and form the cortical plate, where they temporarily settle according to an "inside-out" gradient of positioning (Angevine and Sidman, 1961; Rakic, 1974; Bayer and Altman, 1991). A hypothesis that the cortical areas of the adult brain are mapped in the ventricular zone of the embryonic brain was developed in conjunction with the observation of the radial cell migration occurring in the embryonic cortex (Rakic, 1988). Recent studies with recombinant retroviruses (Walsh and Cepko, 1988, 1992; Austin and Cepko, 1990), chimeric and transgenic mice (Tan and Breen, 1993; Tan et al., 1995; Soriano et al., 1995), and fluorescent labeling (O'Rourke et al., 1992), however, revealed that the tangentially migrating cells in the intermediate zone (IZ) were not negligible in the embryonic neocortex. Because the tangential migration of neurons was not integrated in the hypothesis by Rakic (1988), to determine how the cortical areas are specified it is necessary to investigate the nature and implications of the tangentially migrating cells in detail.

There are two kinds of hypotheses concerning the destination and fate of tangential cell migration in the IZ, one of which has considered only that the tangentially migrating cells will be incorporated into the cortical plate and the other suggests that some of them will not join the cortical plate. Although GABA immunoreactive (GABA-IR) cells have been observed in the embryo

Received June 9, 1997; revised Aug. 13, 1997; accepted Aug. 20, 1997.

This study was supported by Grant-in-Aid 07279217 from the Ministry of Education, Science and Culture for Scientific Research on Priority Areas related to "Functional Development of Neural Circuits." We acknowledge the important advice from Dr. M. Ogawa.

Correspondence should be addressed to Dr. Nobuaki Tamamaki, Department of Anatomy, Fukui Medical School, Matsuoka, Fukui 910-11, Japan.

Copyright (C) 1997 Society for Neuroscience $0270-6474 / 97 / 178313-11 \$ 05.00 / 0$ neocortex of several species (Lauder et al., 1986; Van Eden et al., 1989; Cobas et al., 1991; Del Rio et al., 1992; Schwartz and Meinecke, 1992; Yan et al., 1992), Van Eden et al. (1989) suggested that the GABA-IR cells in the lower IZ were migrating dorsomedially along the IZ, based on their morphology. DeDiego et al. (1994) also advanced the idea that the GABA-IR cells in the $\mathrm{IZ}$ were a distinct population and were migrating toward the dorsal cortex. However, these suggestions have been derived from immunohistochemical observations of embryos at various stages and have not been supported by direct and reliable evidence to show cell migration.

So far, the tangentially migrating cells in the neocortex have only been thought to be originating in the ventricular zone of the neocortex (O'Rourke et al., 1992) or the ventricular zone of the corticostriatal sulcus (Menezes and Luskin, 1994).

In this study we visualized the migrating cells by injecting 1,1'-dioctodecyl-3,3,3',3'-tetramethylindocarbocyanine perchlorate (DiI) in vivo and in vitro and examined the direction of the cell migration by disturbing the migration with a cut made in the neocortex. This paper shows that most of the tangentially migrating neurons in the IZ are originating in the lateral ganglionic eminence (LGE) and are different from the neurons that join the cortical plate.

A preliminary report about the origin of the tangentially migrating cells in the IZ has been published previously (Tamamaki et al., 1996).

\section{MATERIALS AND METHODS}

Immunohistochemistry. For microtubule-associated protein 2 (MAP2) immunohistochemistry (De Camilli et al., 1984; Bernhardt et al., 1985), embryos from embryonic day (E) 14 through E20 were immersion-fixed or perf used with $70 \%$ ethanol, and brains were removed from them. The brains were post-fixed in the ethanol solution overnight, dehydrated with 
an ethanol series, and embedded in paraffin. Sections $(7 \mu \mathrm{m})$ were deparaffinized and treated with $0.3 \%$ hydrogen peroxide in methanol for $30 \mathrm{~min}$, before incubation in 1:500 anti-MAP2 monoclonal mouse IgG (Chemicon, Temecula, CA). Then the sections were processed with avidin-biotin-HRP kit (ABC kit, Vector Laboratories, Burlingame, CA). MAP2-positive sites were visualized using the nickel-enhanced diaminobenzidine (Ni-DAB) method.

For GABA immunohistochemistry, embryos from E14 through E20 were immersion-fixed or perfused with a fixative containing $0.5 \%$ glutaraldehyde, $4 \%$ paraformaldehyde and $0.1 \mathrm{M}$ phosphate buffer $(\mathrm{PB}), \mathrm{pH}$ 7.4. Brains of the embryos were removed and post-fixed for $2 \mathrm{hr}$ with the same fixative. After several rinses in PBS (0.1 M PB, pH 7.4, and 0.9\% $\mathrm{NaCl}$ ), the brains were embedded in $15 \%$ gelatin in PBS and post-fixed overnight with the same fixative. After several more rinses in PBS, the gelatin block was cut into $100-\mu \mathrm{m}$-thick sections with a microslicer. The sections were incubated in anti-GABA rabbit polyclonal antibody (1: 40,000; a gift from Dr. H. Kimura, Shiga Medical School) in PBS with 5\% bovine serum albumin (BSA). Immunoreactive sites were visualized using an ABC kit and the Ni-DAB method.

5-Bromo-deoxyuridine $(B r d U)$ and $M A P-2$ double staining. BrdU solution $(5 \mu \mathrm{g} / \mathrm{gm}$ in sterile physiological saline and $0.007 \mathrm{~N} \mathrm{NaOH}$ ) was injected into the maternal peritoneal cavity of two rats at each different gestational stage (E12, E13, E14, E15, E16). The injections for each rat were done six times at $2 \mathrm{hr}$ intervals (Miller and Nowakowski, 1988). Fetuses were allowed to develop, and under deep anesthesia they were perfused on E17 with $70 \%$ ethanol. After serial treatments as described above, paraffin sections $(7 \mu \mathrm{m})$ were processed twice for immunohistochemistry with anti-BrdU mouse monoclonal IgG (1:150 in PBS with 5\% BSA; Becton Dickinson, Mountain View, CA) and anti-MAP2 mouse monoclonal IgG (1:400 in PBS with 5\% BSA). Deparaffinized sections were treated with $0.3 \%$ hydrogen peroxide in methanol for $30 \mathrm{~min}$, denatured with $3 \mathrm{~N} \mathrm{HCl}$ for $30 \mathrm{~min}$, and incubated in anti-BrdU overnight. Then, immunoreactive sites were revealed by the process using the ABC kit and the Ni-DAB method. The sections colored with the Ni-DAB were incubated with anti-MAP2 antibody overnight, processed with the ABC kit, and colored once again, but this time the simple DAB method was used. Thus, the somata of the BrdU-positive cells were in black, and the processes of cells in the IZ were in brown.

Disturbance of cell migration with a horizontal cut. To disturb the tangential cell migration in the IZ, we made a horizontal cut in the embryonic neocortex (Berry and Hollingworth, 1973). Eight pregnant rats with E15 or E16 embryos were deeply anesthetized with pentobarbital $(50 \mathrm{mg} / \mathrm{kg}$, i.p.) and received abdominal laparotomies to expose their uteri. From outside of each uterus, a 27 gauge needle was inserted into the amniotic cavity to drain amniotic fluid. A 30 gauge needle, of which the tip was bent in a right angle, was inserted into the surface of the neocortex. The neocortical wall was cut horizontally, more than $1 \mathrm{~mm}$ at the middle level, by pushing the needle into the lateral ventricles. Forty-eight embryos with a horizontal cut were left to develop for $24 \mathrm{hr}$. Then the embryos were perfused with $70 \%$ ethanol and processed for MAP2 immunohistochemistry as described above.

In vivo DiI staining of tangentially migrating cells. Four pregnant rats with E16 embryos were deeply anesthetized with pentobarbital (50 $\mathrm{mg} / \mathrm{kg}$, i.p.) and received abdominal laparotomies to expose their uteri. A small amount of DiI powder was put into a 30 gauge needle from its tip, and the DiI powder on the surface of the needle was wiped off. To eject the DiI powder, a thin steel wire was also installed into the needle from its opposite end. After drainage of amniotic fluid, the needle with DiI was held vertically to the embryo's head and inserted through the uterine wall into a different point of the telencephalon in each embryo. Two days after the injection, 24 E18 embryos were perfused with a fixative (4\% paraformaldehyde in $0.1 \mathrm{M} \mathrm{PB})$, and their brains were recovered. The brains were post-fixed with the same fixative overnight. Then the brains were embedded in gelatin as described in the GABA immunohistochemistry. The brains in gelatin blocks were cut into $100 \mu \mathrm{m}$ frontal sections with a microslicer. The serial sections were observed with a fluorescent microscope or a confocal microscope (Olympus, GB-200).

In vitro DiI staining of tangentially migrating cells. Thirty-six E17 embryos were obtained from six anesthetized pregnant rats. Under sterile conditions, the embryo brains were cut into rostral and caudal halves. The rostral half of the embryo brain contained most of the LGE and medial ganglionic eminence (MGE) as well as the neocortex. Autoclaved bamboo fibers were rinsed in DiI solution dissolved in dimethylformamide and air-dried. Short pieces of the bamboo fiber with DiI were inserted at various points, i.e., one point per brain (LGE, 20; MGE, 6; thalamus, 2; temporal cortex, 4; ventral to the internal capsule, 4). Then the brain was transferred to a culture dish with proper medium. The medium contained $10 \%$ fetus calf serum, $20 \mu \mathrm{g} / \mathrm{ml}$ ampicillin, and 50 $\mu \mathrm{g} / \mathrm{ml}$ streptomycin in DMEM (Life Technologies, Gaithersburg, MD). The rostral-half brains in culture dishes were incubated in a $\mathrm{CO}_{2}$ incubator $\left(\mathrm{CO}_{2} 5 \% ; 37^{\circ} \mathrm{C}\right)$ for $24 \mathrm{hr}$ with slow agitation. After the incubation, the brain tissue was fixed and rinsed in the same fixative used in the in vivo experiment, embedded in gelatin, and cut into frontal sections as described above.

\section{RESULTS}

\section{MAP2-IR and GABA-IR cells in the IZ}

Both the MAP2-IR and GABA-IR cells in the IZ of the embryo neocortex started to appear from the lateral region near the corticostriatal sulcus at E14. As the embryo developed, the MAP2-IR and GABA-IR cells in the IZ were also found in the dorsal region of the cortex. However, the cell density of the GABA-IR cells in the IZ had decreased in the lateral region, especially by E19, and they were distributed primarily in the dorsomedial and medial region of the cortex. MAP2-IR cells in the IZ were also slightly reduced in the lateral region after E18. E17 is the stage at which the MAP2-IR and GABA-IR cells in the IZ prevailed throughout the entire cortex (the lateral, dorsal, and medial region of the cortex). Therefore, all of the following observations and experiments were performed at E16, E17, or E18.

Previously, there were several studies that described the MAP2-IR and GABA-IR cells in the IZ (Lauder et al., 1986; Van Eden et al., 1989; Cobas et al., 1991; Del Rio et al., 1992; Ferrer et al., 1992; Schwartz and Meinecke, 1992; Yan et al., 1992), and most of their findings were consistent with our observation, including the observations above. In the remainder of this report, important points that were not mentioned or sufficiently emphasized in the previous studies will be described.

MAP2 and GABA immunohistochemistry revealed a stratified structure of the E17 neocortex (Fig. $1 A, B)$. MAP2 immunoreactivity varied from layer to layer, whereas three GABA-IR layers (the marginal zone, the subplate, and the lower IZ) were stained similarly (Fig. 1B). MAP2-IR cells in the marginal zone were stained with medium-level intensity. MAP2 immunoreactivity in the cortical plate, the subplate, the upper IZ, and the ventricular zone were weakly stained or at background level. In the lower IZ, however, there was sparse but the most intense immunoreactivity. The intense immunoreactivity was sometimes found also in the ventricular zone (Fig. $1 A$, arrows). With higher magnification, the intense immunoreactivity was found mostly in bipolar cells with tangentially directed processes (Fig. $1 C$ ). Because the MAP2-IR cells in the IZ had intense staining, only these cells were obvious in the figure with low magnification (Fig. 1A). Therefore, the protocol we used for MAP2 immunohistochemistry was very useful for revealing the MAP2-IR cells in the IZ and to discriminate them from the neurons in other strata.

The dorsomedial direction of the embryo brain is on the left in all panels in Figure 1. When the tangentially directed long and thick processes were observed as a structure continuous to the cell somata, they were on the dorsomedial side (left side) of the cell somata in most cases (Fig. $1 C-E$ ). We rarely encountered the MAP2-IR or GABA-IR cells with long processes directed vertically or in the opposite direction (ventrolateral direction) in the IZ. Sometimes a short process was observed on the side opposite to the long process. Most GABA-IR cells near the corticostriatal sulcus were bipolar in shape, and the long process had no 

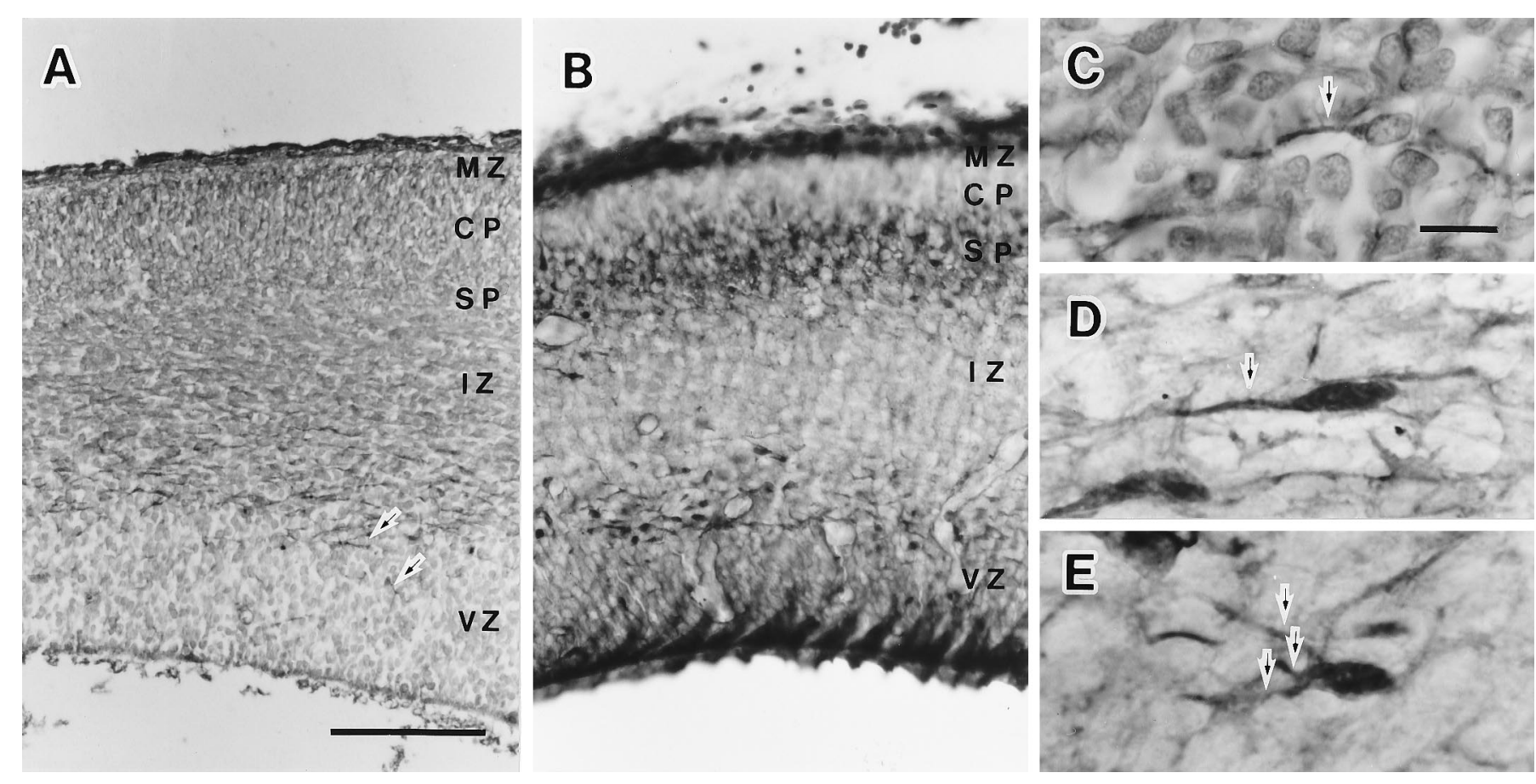

Figure 1. MAP2 and GABA immunohistochemistry in the E17 rat embryonic neocortex. The left side of all of these panels is arranged to face the dorsomedial direction. Most immunoreactive cells in the lower IZ had long processes directed dorsomedially. The processes were not branched in the temporal cortex but had several branches in the dorsal cortex. MAP2-IR cells in the IZ were stained most strongly and were most obvious even with low magnification. GABA immunohistochemistry equally stained three layers (the marginal zone, the subplate, and the IZ). $A$, MAP2 immunohistochemistry on the embryonic neocortex. $B$, GABA immunohistochemistry. $C$, MAP2-IR cells in the IZ of the temporal cortex. $D$, GABA-IR cells in the IZ of the temporal cortex. $E$, GABA-IR cells in the IZ of the dorsal cortex. Arrows in $A, C, D$, and $E$ indicate the MAP2-IR or GABA-IR long processes. $C P$, Cortical plate; $I Z$, intermediate zone; $M Z$, marginal zone; $S P$, subplate; $V Z$, ventricular zone. Scale bar: $A, 100 \mu \mathrm{m}$, also applies to $B ; C, 10 \mu \mathrm{m}$, also applies to $D$ and $E$.

branches (Fig. 1D). However, the long process was sometimes branched in the dorsal cortex (Fig. $1 E$ ).

The features of the GABA-IR cells and the MAP2-IR cells in the IZ coincided well and were similar to the cells in migration in the embryonic neocortex (Rakic, 1972). A long process directed dorsomedially looked like a leading process, and a short process looked like a tailing process of the cells in migration. Cells migrating in a radial direction have been proposed to follow glial guides and those in a tangential direction have been proposed to follow preexisting axonal pathways (Rakic, 1990). To find candidates for migratory guides for MAP2-IR cells in the IZ, we observed the serial frontal sections with Nomarski optics. In the lateral region of the cortex, their distribution seemed to coincide well with the corticothalamic and the thalamocortical fiber pathways. In the dorsal cortex, however, MAP2-IR cells were found primarily in the lower IZ, whereas the fiber pathways were found in the upper IZ. Nomarski optic image did not reveal notable structures for migratory guides in the lower IZ.

\section{MAP2 immunohistochemistry after making a horizontal cut in the neocortex}

The GABA-IR and MAP2-IR cells in the IZ seemed to be migrating tangentially (Fig. 1). Moreover, according to the direction of extending long processes, most of them seemed to be migrating toward the dorsomedial cortex, so we hypothesized that if an obstacle were placed in the cortex to disturb the cell migration, these MAP2-IR cells would accumulate on the ventral side of the obstacle and would be lacking on the dorsal side of it. On the basis of this assumption, a horizontal cut was made in the neocortex of the E15 or E16 embryos.
The cut was made with a 30 gauge needle in the middle level of the neocortex, as shown in Figure $2 C$. In every E15 embryo neocortex, there were MAP2-IR cells in the preplate and in the IZ (Fig. 2B). The MAP2-IR cells in the IZ were also found around the level of the horizontal cut and had long processes directed mostly in the dorsomedial direction. Therefore, when the horizontal cut was made, MAP2-IR cells in the IZ were already present on the dorsal side of the cut. The embryo then was allowed to develop normally in the maternal uterus for $24 \mathrm{hr}$.

Six E16 and 10 E17 embryos with a horizontal cut in their neocortices were recovered for MAP2 immunohistochemistry. In two of six E16 embryos and 3 of 10 E17 embryos, the horizontal cut remained open (Fig. $2 C$ ). The IZ of the contralateral hemisphere contained many MAP2-IR cells with long processes that were directed dorsally (Fig. 2D). The IZ on the ventral side of the horizontal cut contained more MAP2-IR cells with processes that were directed either rostrally or caudally and appeared as short fragments of processes in the frontal sections (Fig. $2 F$ ). As we expected, the MAP2-IR cells were drastically reduced in the IZ on the dorsal side of the horizontal cut (Fig. 2E) and accumulated on the ventral side of the horizontal cut (Fig. $2 F$ ). The reduction and the accumulation of MAP2-IR cells was quantified by counting MAP2-IR somata or processes contained in a unit area including the IZ, the subventricular zone, and the ventricular zone. The area including the IZ, the subventricular zone, and the ventricular zone shown in Figure $2 D$ was $0.045 \mathrm{~mm}^{2}$ and contained 59 MAP2-IR cells. In areas of the same size measured at a point contralateral to the horizontal cut or from the cut side in Figure $2 C, E$, there were 41 and $10 \mathrm{MAP} 2-\mathrm{IR}$ cells, respec- 


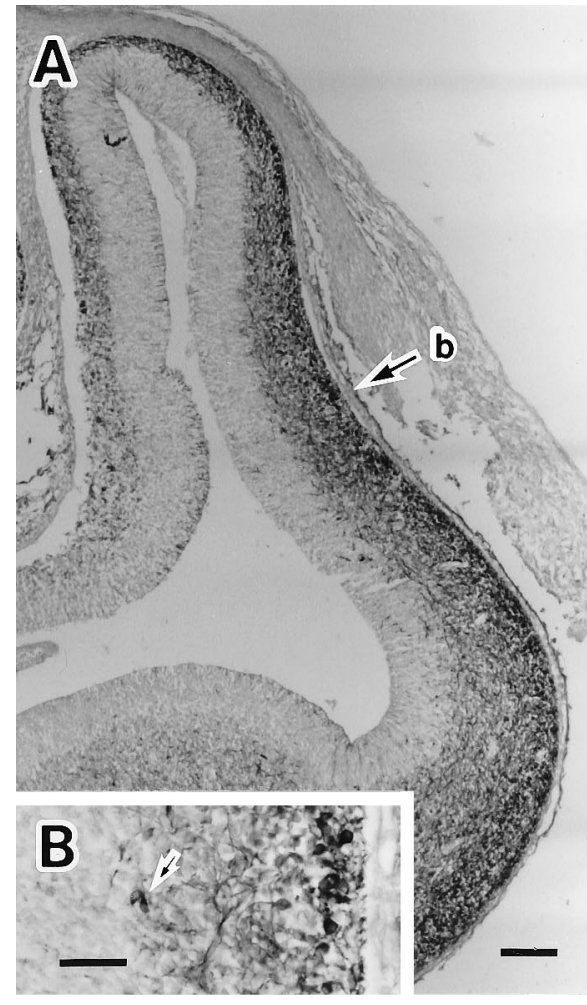

Figure 2. Cell migration examined after an obstacle to migration at E15 or E16 was made and detected with MAP2 immunohistochemistry at E16 or E17. MAP2-IR cells in the IZ were lost on the dorsal side of the horizontal cut (the obstacle), which was made in the middle level of the neocortex. They had accumulated on the ventral side of the horizontal cut. $A$, MAP2 immunohistochemistry on the frontal section of the E15 embryonic brain. An arrow (b) indicates the level where a horizontal cut was made. $B$, High magnification photograph of area indicated with an arrow $(b)$ in $A$. Arrows indicate the MAP2-IR cells in the IZ. $C$, MAP2 immunohistochemistry on the frontal section of the E16 brain with a horizontal cut in the neocortex. An asterisk indicates the point of the horizontal cut made in the neocortex. Arrows $(d, e$, and $f$ ) indicate the points where the photographs in $D-F$ were taken, respectively. $D$, MAP2-IR cells in the neocortex of the hemisphere contralateral to the horizontal cut. Many MAP2-IR cells (arrow) were observed in the IZ. E, MAP2 immunohistochemistry on the dorsal side of the cut. The MAP2-IR cells (arrow) were reduced drastically in the IZ. F, MAP2 immunohistochemistry on the ventral side of the cut. MAP2-IR cells (arrow) were accumulated in the IZ. Arrowheads at cor$n e r s$ in $D-F$ indicate the direction in which the dorsal cortex locates. Scale bars: $A, 100 \mu \mathrm{m} ; B, 50 \mu \mathrm{m} ; C, 500 \mu \mathrm{m}$; shown in $D$ for $D, E, F, 50 \mu \mathrm{m}$.
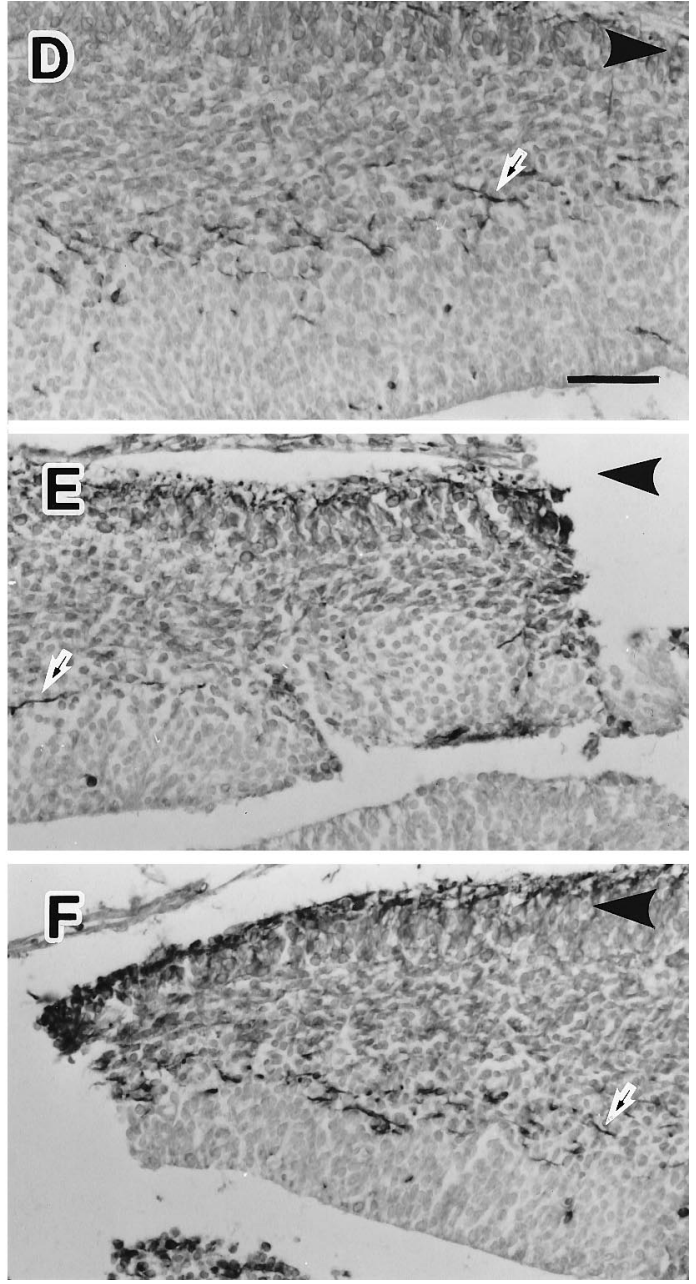

Table 1. Accumulation and reduction of MAP2-IR cells in the IZ caused by the horizontal cut made in the neocortex

\begin{tabular}{|c|c|c|c|c|c|}
\hline & Contralateral side & Ventral side & Dorsal side & Ventral/contralateral & Dorsal/contralateral \\
\hline \multicolumn{6}{|l|}{ E16 } \\
\hline Case 1 & 36.3 & 71 & 12 & 1.95 & 0.33 \\
\hline Case 2 & 50.3 & 93 & 15 & 1.85 & 0.30 \\
\hline \multicolumn{6}{|l|}{ E17 } \\
\hline Case 3 & 39.7 & 69.3 & 3.67 & 1.75 & 0.09 \\
\hline Case 4 & 53.3 & 97 & 9 & 1.82 & 0.17 \\
\hline Case 5 & 67.7 & 112 & 5.33 & 1.66 & 0.08 \\
\hline Mean $\pm \mathrm{SD}$ & $49.5 \pm 12.4$ & $88.5 \pm 18.2$ & $9 \pm 4.66$ & $1.80 \pm 0.11$ & $0.19 \pm 0.12$ \\
\hline
\end{tabular}

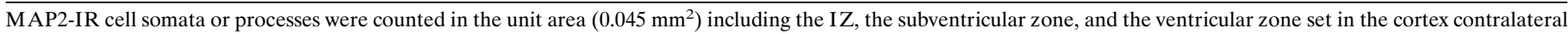

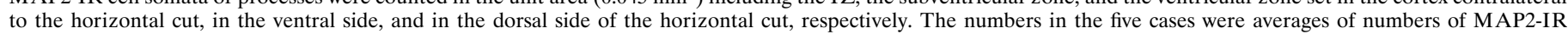
structures obtained from three different rostrocaudal levels and their ratios. The last line shows mean \pm SD of the five cases.

tively. The number of these cells was obtained at three different rostrocaudal levels in each of the five cases and is shown in Table 1 as their averages. Compared with the contralateral side, in the averages of the five cases, MAP2-IR cells had increased $80 \%$ on the ventral side and decreased $80 \%$ on the dorsal side of the horizontal cut. There was no case of a complete lack of the cells on the dorsal side of the horizontal cut. The arrow in Figure $2 E$ indicates a MAP2-IR cell with a long process directed ventrolaterally. There was a slight shrinkage in the marginal zone, the cortical plate, and the subplate on the dorsal side of the horizontal cut.
Some embryos had a scar from the horizontal cut, but after the cut was made in the neocortex, the sides of the cut seemed to fuse together. In these embryos, MAP2-IR cells in the IZ were found even in the scar. They had not decreased on the dorsal side of the scar and had not accumulated on the ventral side but seemed to migrate by crossing the scar. The other embryos had a severely damaged telencephalon and were not used for any analysis.

The results shown here strongly supported the hypothesis that most of the cells with intense MAP2 immunoreactivity in the IZ would be migrating toward the dorsomedial cortex, and that the MAP2-IR long processes would be regarded as their leading 
processes. To confirm the cell migration, the lipophilic vital staining dye DiI was introduced into living tissue in vivo and in vitro in the following experiments.

\section{Tangential cell migration revealed by Dil injection in vivo}

Four samples had a neat and small injection site, and the trajectories of needle penetration in the four samples were not contaminated with DiI powder. Every section with DiI staining from these four samples was observed and photographed under a fluorescent microscope.

In every case, DiI-labeled cells were observed outside the injection site. When the DiI was injected into the IZ of the neocortex, many DiI-labeled cells with a Golgi-like image were found in the IZ on the dorsal side of the injection site (Fig. $3 A$ ). The DiI labeling revealed that the cells in the IZ had a long and thick process as well as a thin and short one (Fig. $3 B$ ). The feature of DiI-labeled cells in the IZ resembled the cells in migration (Rakic, 1972), the MAP2-IR and the GABA-IR cells in the IZ (Fig. 1). The DiI-labeled cells with Golgi-like images were observed when migrating cells came out from the injection site in vivo (O'Rourke et al., 1992). Therefore, we regarded the DiIlabeled cells with a Golgi-like image as migrating cells and the long process as a leading process. Most of the leading processes were directed dorsomedially. The leading processes were often branched in the dorsal cortex. The cells in Figure $3 C-E$ might be multipolar cells that originated as migrating bipolar cells and later settled in the IZ. On the other hand, the DiI labeling in the subplate and the cortical plate appeared as many small granules in their somata and sometimes in the thick dendrites. The feature of DiI labeling in vivo was characteristic of retrogradely labeled neurons (Tamamaki and Nojyo, 1995) and distinguished from the labeling in the migrating cells.

The data of DiI labeling in vivo were also used to analyze the number and direction of the migrating cells. Direction of cell migration was regarded as the direction in which the leading process was extended. In the case in which migrating cells had branched leading processes or had turned into multipolar cells in the dorsal or medial region, the direction of migration was judged as the direction opposite the thin tailing process. In case $A$ of Figure 4 , DiI crystal was injected into the medial region of the telencephalic vesicle. Ten migrating cells were observed in the serial frontal sections. All of them were directed ventrally toward the corticoseptal boundary where the corpus callosum was going to be formed. Some of them were found under the pia mater of the medial region of the telencephalic vesicle. Concerning the rostrocaudal distribution, the migrating cells were found in five serial sections obtained from around the level of the injection site (within $500 \mu \mathrm{m}$ width). They migrated only several hundred micrometers in $2 \mathrm{~d}$.

In case $\mathrm{B}, \mathrm{DiI}$ crystal was injected into the dorsal wall of the telencephalic vesicle (dorsal cortex) (Fig. 3C). Nineteen migrating cells were observed in serial frontal sections. Eighteen cells were directed ventrally in the medial wall of the telencephalic vesicle. Only one cell was found migrating laterally. They were distributed in six serial sections obtained from around the level of the injection site. They migrated $<1 \mathrm{~mm}$ in $2 \mathrm{~d}$.

The number of labeled migrating cells was drastically increased as the injection site was shifted from the dorsal cortex to the temporal cortex. In case $\mathrm{C}$, DiI crystal was injected into the corticostriatal sulcus, and the most numerous migrating cells were found advancing toward the dorsomedial cortex along the IZ (Fig.
$3 A$ ). In $2 \mathrm{~d}$, migrating cells reached the dorsal cortex from the corticostriatal sulcus. More than 500 migrating cells were observed in 12 serial frontal sections $(1.2 \mathrm{~mm})$, seven of which were obtained from the rostral side of the injection site. Most of them were directed dorsally along the IZ. Several migrating cells were also observed in the temporal cortex.

To determine the origin of the migrating cells, we injected DiI at various points in the basal ganglia (ventral or dorsal to the internal capsule, LGE, or MGE). In case D, DiI crystal was injected into the ventricular zone between the MGE and LGE; in total, we found $>500$ migrating cells in the neocortex (Fig. 4D). The labeled migrating cells from the LGE were distributed in 17 serial frontal sections in the rostrocaudal direction, 10 of which were obtained from the rostral side of the injection site. Most of them were directed dorsally and reached the dorsal cortex in $2 \mathrm{~d}$. Some of them $(<50)$ were directed toward the temporal cortical surface with radial migration. With higher magnification, many migrating cells were found rounding the corner of the corticostriatal sulcus (Fig. 3G). Some of them were also discovered in the marginal zone or cortical plate of the temporal cortex (Fig. $3 F$ ).

\section{Origin of tangentially migrating cells examined in vitro}

To eliminate the possibility of mistaking retrogradely labeled neurons for migrating cells in the in vivo experiment, we performed a DiI labeling of migrating cells in vitro. Pieces of DiIimpregnated bamboo fiber were inserted into various points of the embryonic brains (LGE, 20; MGE, 6; thalamus, 2; temporal cortex, 4; ventral to the internal capsule, 4). After a 24 hr culture, the rostral halves of the brains were cut into frontal sections. Depending on the condition of the culture and injection site, the number of labeled cells varied greatly, but after the injections into the LGE or MGE, two or three sections from the injection site surface usually contained DiI-labeled cells with Golgi-like images. The labeled cells had a long and a short process, so we regarded them as migrating cells. The number of migrating cells were counted in each region of the sections and presented in five cases (Table 2).

After DiI injection into the LGE, several labeled cells crossed the boundary between the striatum and the neocortex and were found in the IZ of the neocortex (Fig. 5B,C). The DiI-labeled migrating cells were found not only in the IZ but also in the LGE and MGE and along the internal capsule. A migrating cell indicated by the arrow $(d)$ in Figure $5 B$ was coursing in the ventromedial and caudal direction, along the internal capsule to an unknown destination (Fig. 5D).

After DiI injection into the MGE, migrating cells were revealed in the LGE and in the internal capsule, but not in the neocortex. In one case of DiI injection into the temporal cortex, a few migrating cells were found in the marginal zone and cortical plate of the neocortex. After DiI injection into the thalamus or the regions ventral to the internal capsule, only anterogradely labeled fibers were found in the neocortex, and no migrating cells were detected anywhere.

\section{Double staining of BrdU and MAP2 immunohistochemistry}

To know the birth dates of the migrating cells in the IZ, double staining for BrdU and MAP2 immunohistochemistry was performed in the E17 embryonic brain. BrdU was injected at E12, E13, E14, E15, and E16 into the maternal peritoneal cavity, and the embryos were fixed at E17. BrdU-positive nuclei were colored in black and the MAP2-IR structures were colored in brown (Fig. 

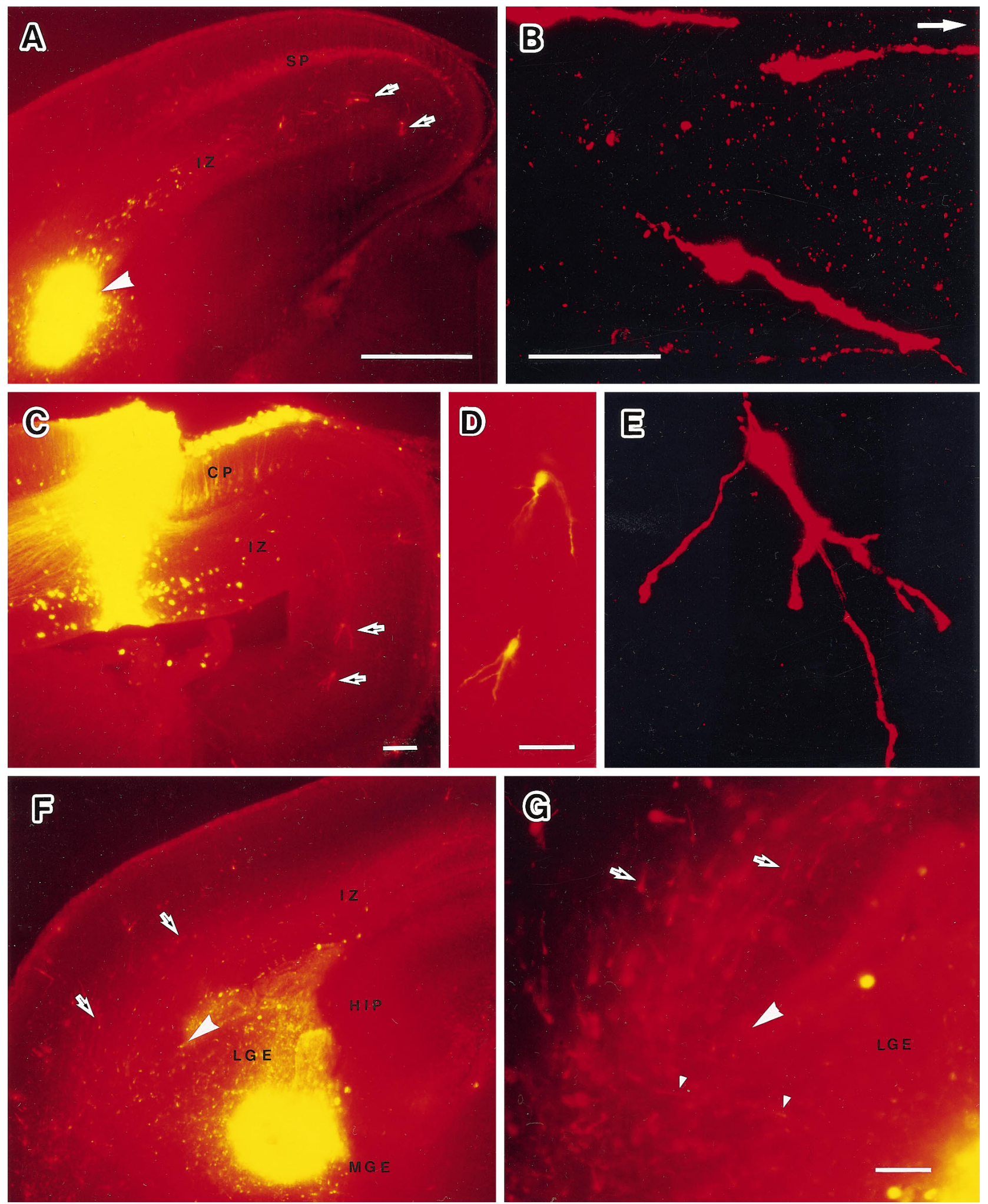

Figure 3. Cell migration observed in vivo by injecting DiI into the E16 embryonic brain and examined at E18. $A$, A frontal section of an embryonic brain through an injection site at the corticostriatal sulcus. Many migrating cells were observed in the IZ of the cortex. At the same time many retrogradely labeled cells were observed in the subplate and the cortical plate. $B$, A confocal microphotograph of migrating cells in the IZ of the temporal cortex. A white arrow indicates the dorsal direction. $C$, A frontal section of an embryonic brain through an injection site in the dorsal cortex. $D$, Migrating cells in $C$ with higher magnification. $E$, A confocal microphotograph of migrating cells in the IZ of the dorsal cortex. $F$, A frontal section of an embryonic brain through an injection site in the LGE. $G$, Migrating cells at the corticostriatal sulcus. $C P$, Cortical plate; $H I P$, hippocampus; $I Z$, intermediate zone; $L G E$, lateral ganglionic eminence; $M G E$, medial ganglionic eminence; $S P$, subplate. Dorsal direction is the top of all panels except $B$. Arrows indicate the migrating cells. Large arrowheads indicate the corticostriatal sulcus. Small arrowheads indicate migrating cells crossing the corticostriatal boundary. Scale bars: $A, 500 \mu \mathrm{m}$, also applies to $F ; B, D, 50 \mu \mathrm{m} ; E$ (shown in $B$ ), $50 \mu \mathrm{m} ; C, G, 100 \mu \mathrm{m}$. 
A
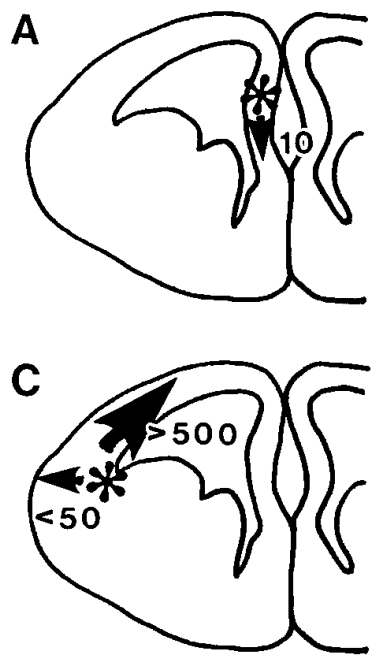
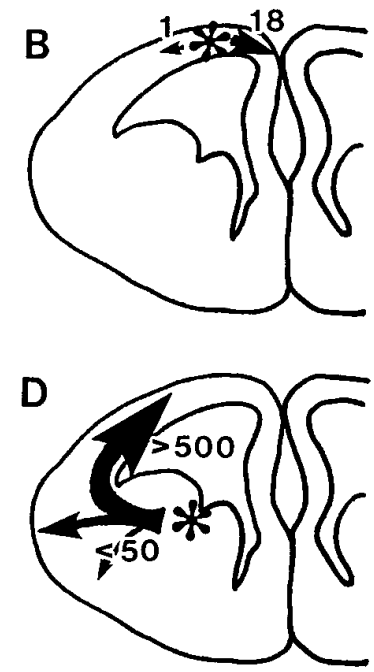

Figure 4. Schematic diagrams to summarize the direction and number of migrating cells observed in vivo after DiI injection into the embryonic brain. Asterisks indicate the injection sites. Arrows indicate the direction of cell migration. Size of arrows and the number nearby stand for the number of cells migrating in each direction. $A$, DiI crystal was injected into the medial wall of the telencephalic vesicle. Ten migrating cells were observed outside of the injection site. All of them were directed ventrally toward the corticoseptal boundary. Regarding the rostrocaudal distribution, the migrating cells were found in five serial sections obtained from around the level of the injection site (within $500 \mu \mathrm{m}$ width). $B$, DiI crystal was injected into the dorsal wall of the telencephalic vesicle (dorsal cortex). Nineteen migrating cells were observed. Eighteen cells were directed ventrally in the medial wall of the telencephalic vesicle. Only one cell was found migrating laterally. The cells were distributed in six serial sections obtained from around the level of the injection site. $C$, DiI was injected into the corticostriatal sulcus. More than 500 migrating cells were observed in 12 serial frontal sections $(1.2 \mathrm{~mm})$ obtained more from the rostral side of the injection site. Most of them were directed dorsally along the IZ. Several migrating cells were also observed in the temporal cortex. $D$, DiI was injected into the ventricular zone between the MGE and LGE, and in total $>500$ migrating cells were also observed in this case. The labeled migrating cells from the LGE were distributed more widely in the rostrocaudal direction but tilted toward the rostral direction (in 17 serial frontal sections obtained more rostrally to the injection site). Most of them were directed dorsally. Some of them $(<50)$ were directed toward the temporal cortical surface with radial migration.

Table 2. Dil-labeled migrating cells observed in vitro

\begin{tabular}{lllclr} 
& NC & LGE & MGE & TC & IC \\
\hline Case 1 (LGE) & 5 & 47 & 0 & 2 & 6 \\
Case 2 (LGE) & 3 & 11 & 0 & 3 & 0 \\
Case 3 (MGE) & 0 & 63 & 44 & 5 & 17 \\
Case 4 (MGE) & 0 & 4 & 7 & 1 & 1 \\
Case 5 (TC) & 3 & 0 & 0 & 5 & 0
\end{tabular}

The number of Dil-labeled migrating cells found in various regions were listed for two cases of Dil injection into the LGE, two cases of injection into the MGE, and one case of injection into the temporal cortex. NC, Neocortex; LGE, lateral ganglionic eminence; MGE, medial ganglionic eminence; TC, temporal cortex; IC, internal capsule.

6). BrdU immunohistochemistry after BrdU injection at E13 revealed three immunoreactive cell layers in the E17 neocortex, the marginal zone, the subplate, and the lower IZ. Many BrdUpositive nuclei in the $\mathrm{IZ}$ were elongated in a tangential direction, whereas those in the subplate and the marginal zone were round (Fig. 6A). The elongated nuclei suggest that the cells were in migration tangentially. Most BrdU-positive nuclei in the IZ after

the BrdU injection at E13 were connected to the MAP2-IR processes (Fig. 6B).

Four or five embryos in each BrdU-injection paradigm were analyzed quantitatively (21 embryos in total). The number of MAP2-IR cell somata and the number of MAP2 and BrdU double-labeled cell somata were counted on one side of the IZ in one frontal section. The numbers were counted three times on three different rostrocaudal levels in each embryonic brain, and averages of the numbers were obtained from 21 embryos. The average numbers in 21 embryos were used to make Figure 7, which shows the histogram of birth dates of the MAP2-IR cells in the IZ of the E17 neocortex. The most numerous double-labeled cell somata were found after BrdU injection at E14 (24.1 \pm 1.75$)$. They were also produced at E13 and E15, but at a very low level at E12 and E16. One side of the neocortex in one section at E17 contained $120 \pm 10($ mean $\pm \mathrm{SD} ; n=21)$ MAP2-IR cell somata. Although the BrdU-injection paradigm that we used labeled a part of the MAP2-IR cells in the IZ and the total of doublelabeled cells was $31.3 \%(37.5 / 120)$ of the MAP2-IR cells in the IZ, the peak of the production of the MAP2-IR cells in the IZ was clearly shown at E14, which should be regarded as a value for early-generated neurons in the neocortex

\section{DISCUSSION}

The data obtained from the experiment of DiI injection in vivo and in vitro and from the other experiment in which a horizontal cut was made in the cortex revealed the existence of many tangentially migrating cells in the IZ. A quantitative analysis of the migrating cells in number and in direction indicated the origin, destination, and fate of the cells.

\section{Technical considerations}

When DiI was injected into the embryonic telencephalic vesicle in vivo or in vitro, many cells labeled in Golgi-like manner were found outside of the injection site, especially in the IZ. Most of them were bipolar cells and had a long and a short process. The labeled cells with these features were regarded as migrating cells in the in vitro experiment (De Carlos et al., 1996). Moreover, migration of similar cells was traced with video microscopy (O'Rourke et al., 1992). Therefore, it would be reasonable to regard the DiI-labeled cells with Golgi-like images as migrating cells in this study. From the viewpoint of morphological similarity to the radially migrating cells, previous immunohistochemical and Golgi studies have suggested that the cells in the IZ were migrating tangentially (Valverde et al., 1989; Van Eden et al., 1989; DeDiego et al., 1994). We also made another MAP2 immunohistochemical study and were able to reveal the tangential migration of MAP2-IR cells in the dorsomedial direction by adding the simple operation of a horizontal cut in the neocortex (Fig. 2). As we expected, a disappearance and an accumulation of MAP2-IR cells on the dorsal and ventral sides of the horizontal cut were detected, respectively. Therefore, we were able to assume that the MAP2-IR and GABA-IR cells shown in Figure 1 are also migrating tangentially and that the population of MAP2-IR and GABA-IR cells and of DiI-labeled migrating cells overlap each other.

\section{Tangentially migrating MAP2-positive cells are a distinct population}

The tangentially migrating cells in the IZ were not considered to be incorporated into the cortical plate for two reasons. First, most MAP2-IR cells in the IZ had finished their final cell division by E14 (Fig. 6). Even the cells produced at E15 remained in the 

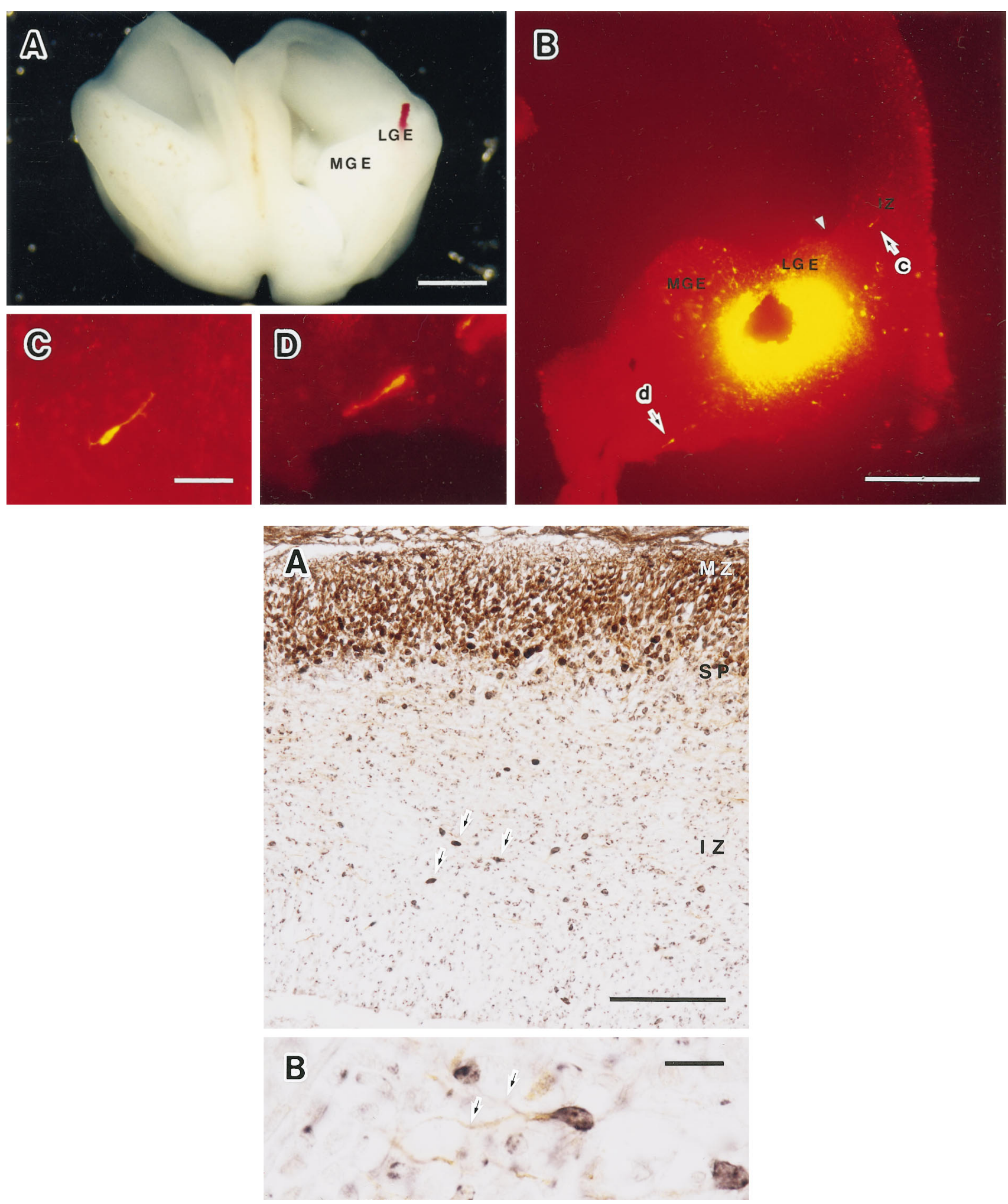

Figure 5. Top. Cell migration observed in vitro by injecting DiI into the LGE of the E16 embryonic brain and cultured for 24 hr (Case 1 in Table 2$)$. $A$, A cultured rostral half of the embryonic brain. $B$, A frontal section through the LGE and the neocortex of the cultured brain. Arrows ( $c$ and $d$ ) indicate the migrating cells in the IZ and the internal capsule shown in $C$ and $D$, respectively. An arrowhead indicates the corticostriatal sulcus. $C$, A migrating cell in the IZ with higher magnification. $D$, A migrating cell in the internal capsule with higher magnification. $L G E$, Lateral ganglionic eminence; $M G E$, medial ganglionic eminence. Scale bars: $A, 1 \mathrm{~mm} ; B, 500 \mu \mathrm{m} ; C, 50 \mu \mathrm{m}$, and also applies to $D$.

Figure 6. Bottom. Double staining for BrdU and MAP2 immunohistochemistry on the embryonic brain after BrdU injection at E13 and fixed at E17. BrdU-positive nuclei were colored in black, and the MAP2-IR structures were colored in brown. BrdU immunohistochemistry after BrdU injection at E13 revealed three immunoreactive cell layers in the E17 neocortex. A, Double staining of MAP2 and BrdU immunohistochemistry. Arrows indicate elongated BrdU-positive nuclei in tangential direction. B, Double-stained cells in the IZ. Arrows indicate the MAP2-IR process connected to the BrdU-positive nucleus. $M Z$, Marginal zone; $S P$, subplate; $I Z$, intermediate zone. Scale bars: $A, 100 \mu \mathrm{m} ; B, 10 \mu \mathrm{m}$. 


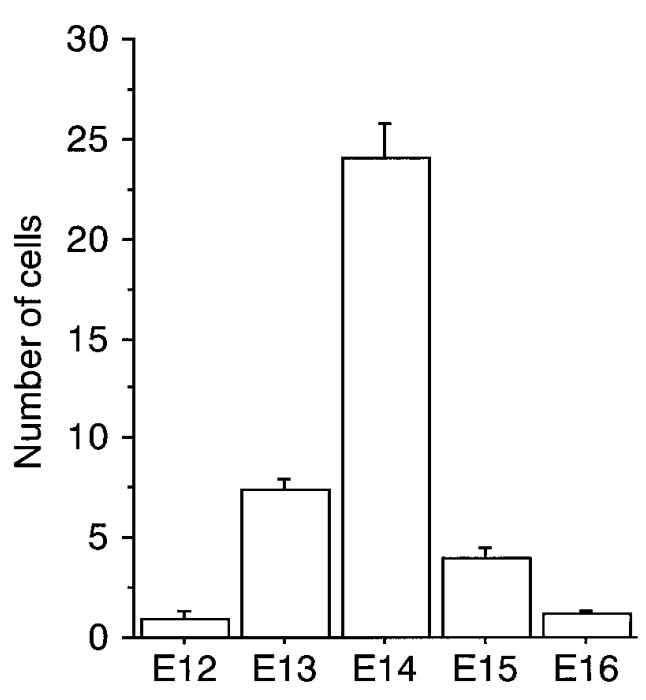

Figure 7. The time of origin of MAP2-IR cells in the IZ of the E17 embryo brain. BrdU was injected at E12, E13, E14, E15, or E16. The number of BrdU and MAP2 double-labeled cells contained in one side of the IZ in one frontal section was obtained from 21 embryo brains. These numbers were used to make the histogram of birth dates of the MAP2-IR cells in the IZ of the E17 neocortex. The most numerous double-labeled cell somata were found after BrdU injection at E14 $(24.1 \pm 1.75 ;$ mean $\pm \mathrm{SD} ; n=5)$.

lower IZ and seemed to be migrating tangentially. According to the birth date and the location of the MAP2-IR cells, they were early-generated neurons similar to the subplate neurons and the cells in the marginal zone (Valverde et al., 1989; Bayer and Altman, 1990, 1991; Ferrer et al., 1992), whereas the cortical plate neurons were produced after E15. The accumulated knowledge about the early-generated neurons in the cortex tells us that these cells are not incorporated into the cortical plate but stay outside or on the bottom of the cortical layers or die after birth (Kostovic and Rakic, 1980, 1990; Chun and Shatz, 1989; Ferrer et al., 1990, 1992; Valverde et al., 1995). Second, if the migrating IZ cells incorporate with the cortical plate, they must reduce the GABA and MAP2 immunoreactivity before entering there. Regarding the Tuj1 immunoreactivity, similar discussion was reported by Menezes and Luskin (1994). If the tangentially migrating cells in the $I Z$ reduce these three markers of maturated neurons from their intracellular space, it means that the cells are undifferentiated. It is hard to believe that such a phenomenon occurs in the embryo neocortex.

On the other hand, the tangentially migrating cells in the IZ and the subplate neurons were considered to be a different population for two reasons. First, the protocol for MAP2 immunohistochemistry used in this study stained the cells in the IZ and the subplate neurons differently (Fig. $1 A$ ). Although the subplate is composed of early-generated neurons (Luskin and Shatz, 1985; Valverde et al., 1989; Bayer and Altman, 1990, 1991) and they were stained intensely in other MAP2 immunohistochemical studies (Cobas et al., 1991; Ferrer et al., 1992; Menezes and Luskin, 1994), MAP2 immunoreactivity among the subplate neurons was weak in this study. Second, the MAP2-IR and GABA-IR cell layer in the IZ appeared as a different cell layer from the preplate or the subplate (Van Eden et al., 1989; Ferrer et al., 1992). There were two GABA-IR cell layers (the preplate and the lower IZ) in the early embryos (E14-E15) and three layers (the marginal zone, the subplate, and the lower IZ) later, after the insertion of the cortical plate. The marginal zone contains different types of cells that have functions different from those of the subplate neurons (Shatz et al., 1988; McConnell et al., 1989, 1990; D’Arcangelo et al., 1995; Ogawa et al., 1995). Similarly, the subplate and the IZ were assumed to have different types of cells and different functions.

The MAP2-IR cells in the IZ were considered as neurons different from the cortical plate neurons and the subplate neurons. In the following discussion and in future study, we would like to call these cells "IZ neurons."

\section{Origin of the tangentially migrating cells}

The disappearance of IZ neurons on the dorsal side of the horizontal cut (Fig. 2) supports the idea that the IZ neurons originate in the ventral side of the telencephalic vesicle. When the injection was limited to the inside of the LGE in the in vitro experiment, we still found the labeled migrating cells in the IZ (Fig. 5). We might observe in a longer period of culture that migrating cells from the MGE enter the neocortex by crossing the LGE. The ventricular zone of the LGE is known to produce tangentially migrating cells (Halliday and Cepko, 1992) that may continue to migrate into the neocortex. Moreover, Anderson et al. (1997) also found that the tangentially migrating cells in the neocortex were originating in the LGE and that the cell migration was lost in the Dlx1 and Dlx2 double mutant mouse. It is clear that the ventricular zone of the neocortex is also the origin of tangentially migrating cells in the IZ (O'Rourke et al., 1992), but in number the majority of the tangentially migrating cells were assumed to be originating in the LGE. The ganglionic eminence is a structure that supplies cells to the primary olfactory cortex in early stage embryos (De Carlos et al., 1996) to the neocortex (Anderson et al., 1997; Tamamaki et al., 1996) and to another structure that is accessible from the internal capsule (Fig. 5D) in the subsequent stages of development, and then to the olfactory bulb in the late stages and after birth (Altman and Das, 1966; Bayer, 1983).

\section{Route, destination, and fate of the tangentially migrating IZ neuron}

As we discussed above, most of the IZ neurons originated in the LGE, migrated dorsally, and entered the neocortex. Some of them might migrate radially to the temporal cortex and then tangentially to the neocortex, as shown by De Carlos et al. (1996). They might follow the glial guide for the radial migration and the thalamocortical fiber pathways for the tangential migration in the lateral region of the cortex. However, the distribution of MAP2-IR cells in the IZ did not coincide with those of the fiber pathway in the dorsal region of the cortex. In addition, the accumulated IZ neurons seemed to migrate along the horizontal cut and then detour to the dorsal cortex (Fig. $2 F$ ). We could not find any axon fibers running along the artificial horizontal cut. We have no clear answer as to what the IZ neurons are using for a guide in the tangential cell migration.

The IZ neurons seemed to develop a multipolar shape (Fig. 3) and were apt to accumulate in the IZ of the dorsal cortex. Actually, Van Eden et al. (1989) found an accumulation of GABA-IR cells there, which corresponded to an area named "the transitional field" by Bayer and Altman (1991). Some labeled IZ neurons reached the pia mater of the medial wall of the telencephalic vesicle and the corticoseptal boundary where the corpus callosum is formed. These regions (the subcortical white matter, the corpus callosum, or subpyramidal strata of the hippocampus 
in matured brain) are the areas suggested as the destinations of the tangentially migrating cells by DeDiego et al. (1994). After birth, many cells were dying in the deep layers of the neocortex (Kostovic and Rakic, 1980, 1990; Ferrer et al., 1990, 1992; Valverde et al., 1995). The IZ neurons were generated early and seemed to be eliminated after birth, indicating that they might be transient neurons.

\section{Possible function of the tangentially migrating IZ neuron}

The IZ neurons are a novel population produced in the ventricular zone of the LGE, crossing the corticostriatal boundary (Shimamura et al., 1995) and migrating tangentially in the IZ of the neocortex. Neither their function nor their role in the embryonic brain is known. A possible function of the IZ neurons is that they may work as a guide for the corticof ugal axon projection. Metin and Godement (1996) reported that MAP2-IR cells in the IZ and LGE interacted with corticof ugal axons. If the IZ neurons project axons to a certain target, the axons may work as pioneers for the corticofugal projection. Recently we found DiI-retrograde labeling in MAP2-IR somata in the IZ after DiI injection into the spinal cord of the newborn rat (Tamamaki, 1995). Elucidation of the functions depends on future studies.

\section{REFERENCES}

Altman J, Das GD (1966) Autoradiographic and histological studies of postnatal neurogenesis. 1. A longitudinal investigation of the kinetics, migration and transformation of cells incorporating tritiated thymidine in neonate rats, with special reference to postnatal neurogenesis in some brain regions. J Comp Neurol 127:337-390.

Anderson SA, Eisenstat D, Shi L, Rubenstein JLR (1997) Interneuron migration from basal forebrain to neocortex: dependence on Dlx genes. Science, in press.

Angevine Jr JB, Sidman RL (1961) Autoradiographic study of cell migration during histogenesis of cerebral cortex in the mouse. Nature 192:766-768.

Austin CP, Cepko CL (1990) Cellular migration patterns in the developing mouse cerebral cortex. Development 110:713-732.

Bayer SA (1983) 3H-thymidine-radiographic studies of neurogenesis in the rat olfactory bulb. Exp Brain Res 50:329-340.

Bayer SA, Altman J (1990) Development of layer I and the subplate in rat neocortex. Exp Neurol 107:48-62.

Bayer SA, Altman J (1991) Neocortical development. New York: Raven.

Bernhardt R, Huber G, Matus A (1985) Differences in the developmental patterns of three microtubule-associated proteins in the rat cerebellum. J Neurosci 5:977-991.

Berry M, Hollingworth T (1973) Development of isolated neocortex. Experientia 29:204-207.

Chun JJM, Shatz CJ (1989) Interstitial cells of the adult neocortical white matter are the remnant of the early generated subplate neuron population. J Comp Neurol 282:555-569.

Cobas A, Fairen A, Alvarez-Bolado G, Sanchez MP (1991) Prenatal development of the intrinsic neurons of the rat neocortex: a comparative study of the distribution of GABA-immunoreactive cells and the $\mathrm{GABA}_{\mathrm{A}}$ receptor. Neuroscience 40:375-397.

D'Arcangelo G, Miao GG, Chen S, Soares HD, Morgan JI, Curran T (1995) A protein related to extracellular matrix proteins deleted in the mouse mutant reeler. Nature 374:719-723.

De Camilli P, Miller PE, Navone F, Theurkauf WE, Vallee RB (1984) Distribution of microtubule-associated protein 2 in the nervous system of the rat studied by immunofluorescence. Neuroscience 11:819-846.

De Carlos JA, Lopez-Mascaraque L, Valverde F (1996) Dynamics of cell migration from the lateral ganglionic eminence in the rat. J Neurosci 16:6146-6156.

DeDiego I, Smith-Fernandez A, Fairen A (1994) Cortical cells that migrate beyond area boundaries: characterization of an early neuronal population in the lower intermediate zone of prenatal rats. Eur J Neurosci 6:983-997.

Del Rio JA, Soriano E, Ferrer I (1992) Development of GABAimmunoreactivity in the neocortex of the mouse. J Comp Neurol 326:501-526.
Ferrer I, Bernet E, Soriano E, Del Rio T, Fonseca M (1990) Naturally occurring cell death in the cerebral cortex of the rat and removal of dead cells by transitory phagocytes. Neuroscience 39:451-458.

Ferrer I, Soriano E, Del Rio JA, Alcantara S, Auladell C (1992) Cell death and removal in the cerebral cortex during development. Prog Neurosci 39:1-43.

Halliday AL, Cepko CL (1992) Generation and migration of cells in the developing striatum. Neuron 9:15-26.

Kostovic I, Rakic P (1980) Cytology and time of origin of interstitial neurons in the white matter in infant and adult human and monkey telencephalon. J Neurocytol 9:219-242.

Kostovic I, Rakic P (1990) Developmental history of the transient subplate zone in the visual and somatosensory cortex of the macaque monkey and human brain. J Comp Neurol 297:441-470.

Lauder JM, Han VKM, Henderson P, Verdoorn T, Towle AC (1986) Prenatal ontogeny of the GABAergic system in the rat brain: an immunocytochemical study. Neuroscience 19:465-493.

Luskin MB, Shatz CJ (1985) Studies of the earliest generated cells of the cat's visual cortex: cogeneration of subplate and marginal zones. J Neurosci 5:1062-1075.

Menezes JRL, Luskin MB (1994) Expression of neuron-specific tubulin defines a novel population in the proliferative layers of the developing telencephalon. J Neurosci 14:5399-5416.

McConnell SK, Ghosh A, Shatz CJ (1989) Subplate neurons pioneer the first axon pathway from the cerebral cortex. Science 245:978-982.

Metin C, Godement P (1996) The ganglionic eminence may be an intermediate target for corticof ugal and thalamocortical axons. J Neurosci 16:3219-3235.

Miller MW, Nowakowski RS (1988) Use of bromodeoxyuridineimmunohistochemistry to examine the proliferation, migration and time of origin of cells in the central nervous system. Brain Res 457:44-52.

Ogawa M, Miyata T, Nakajima K, Yagyu K, Seike M, Ikenaka K, Yamamoto H, Mikoshiba K (1995) The reeler gene-associated antigen on Cajal-Retzius neurons is a crucial molecule for laminar organization of cortical neurons. Neuron 14:899-912.

O'Rourke NA, Dailey ME, Smith SJ, McConnell SK (1992) Diverse migratory pathways in the developing cerebral cortex. Science 258:299-302.

Rakic P (1972) Mode of cell migration to the superficial layers of fetal monkey neocortex. J Comp Neurol 145:61-84.

Rakic P (1974) Neurons in rhesus monkey visual cortex: systematic relation between time of origin and eventual disposition. Science 183:425-427.

Rakic P (1988) Specification of cerebral cortical areas. Science 241:170-176.

Rakic P (1990) Principles of neural cell migration. Experientia 46:882-891.

Schwartz ML, Meinecke ML (1992) Early expression of GABAcontaining neurons in the prefrontal and visual cortices of rhesus monkeys. Cereb Cortex 2:16-37.

Shatz CJ, Chun JJM, Luskin MB (1988) The role of the subplate in the development of the mammalian telencephalon. In: Cerebral cortex: development and maturation of the cerebral cortex (Jones EG, Peters A, eds), pp 35-58. New York: Plenum.

Shatz CJ, Ghosh A, McConnell SK, Allendoerfer KL, Friauf E, Antonini A (1990) Pioneer neurons and target selection in cerebral cortical development. Cold Spring Harb Symp Quant Biol LV:469-480.

Shimamura K, Hartigan DJ, Martinez S, Puelles L, Rubenstein JLR (1995) Longitudinal organization of the anterior neural plate and neural tube. Development 121:3923-3933.

Soriano E, Dumesnil N, Auladell C, Cohen-Tannoudji M, Sotelo C (1995) Molecular heterogeneity of progenitors and radial migration in the developing cerebral cortex revealed by transgene expression. Proc Natl Acad Sci USA 92:11676-11680.

Tamamaki N (1995) Transient intermediate zone neurons project to the spinal cord, the superior colliculus, and the contralateral hemisphere in rats. Neurosci Abstr 21:1509.

Tamamaki N, Nojyo Y (1995) Preservation of topography in the connections between the subiculum, field CA1, and the entorhinal cortex in rats. J Comp Neurol 353:379-390.

Tamamaki N, Fujimori KE, Takauji R (1996) Quantitative analysis of tangentially migrating intermediate zone neurons in embryonic rat neocortex. Neurosci Abstr 22:986.

Tan SS, Breen S (1993) Radial mosaicism and tangential cell disper- 
sion both contribute to mouse neocortical development. Nature 362:638-640.

Tan SS, Faulkner-Jones B, Breen SJ, Walsh M, Bertram JF, Reese BE (1995) Cell dispersion patterns in different cortical regions studied with an X-inactivated transgenic marker. Development 121:1029-1039.

Valverde F, Facal-Valverde MV, Santacana M, Heredia M (1989) Development and differentiation of early-generated cells of sublayer $\mathrm{VIb}$ in the somatosensory cortex of the rat: a correlated Golgi and autoradiographic study. J Comp Neurol 290:118-140.

Valverde F, Lopez-Mascaraque L, Santacana M, De Carlos JA (1995) Persistence of early-generated neurons in the rodent subplate: assess ment of cell death in neocortex during the early postnatal period. J Neurosci 15:5014-5024.

Van Eden CG, Mrzljak L, Voorn P, Uylings HBM (1989) Prenatal development of GABA-ergic neurons in the neocortex of the rat. J Comp Neurol 289:213-227.

Walsh C, Cepko CL (1988) Clonally related cortical cells show several migration patterns. Science 241:1342-1345.

Walsh C, Cepko CL (1992) Widespread dispersion of neuronal clones across functional regions of the cerebral cortex. Science 255:434-440.

Yan XX, Zheng DS, Garey LJ (1992) Prenatal development of GABAimmunoreactive neurons in the human striate cortex. Dev Brain Res 65:191-204. 